\title{
PRAKTIKALITAS DAN EFEKTIFITAS BAHAN AJAR KALKULUS BERBASIS DARING BERBANTUAN GEOGEBRA
}

\author{
Sugama Maskar ${ }^{1}$, Putri Sukma Dewi ${ }^{2}$ \\ ${ }^{1,2}$ Universitas Teknokrat Indonesia, Jl. ZA. Pagar Alam No.9 -11, Labuhan Ratu, Kec. Kedaton, Kota Bandar Lampung \\ Penulis pertama: sugama_maskar@teknokrat.ac.id
}

\begin{abstract}
The program of the Indonesian government through the ministry of education and culture (Kemendikbud) on online learning which started in 2014 is forced to accelerate its implementation massively in 2020 due to the effects of the Covid-19 pandemic that hit the whole world, including Indonesia. Changing traditional learning to full online is certainly a big challenge for educational institutions. Online learning certainly requires relevant support, one of which is teaching materials. This article discusses the development of online calculus-based teaching materials with GeoGebra assistance. The purpose of developing these teaching materials is as an alternative so that online-based calculus learning can run effectively and optimally. The method used to develop these teaching materials is research and development $(\mathrm{R} \& \mathrm{D})$ through testing the practicality and effectiveness of the teaching materials with a instrument questionnaire and basic calculus test on 20 respondents who are students of the Mathematics Education Study Program of Universitas Teknokrat Indonesia who have taken basic calculus course. The results of practicality testing and the effectiveness of this teaching material show that the practicality and effectiveness of this teaching material are in good categories with a test value of 3.36 for practicality and 72.75 for effectiveness. This means that this online-based calculus teaching material assisted by GeoGebra can be implemented in users as an alternative to online-based calculus learning. Based on the evaluation of the practicality and effectiveness of the questionnaire results, this teaching material needs to be maximized in the content section to be able to develop user creativity and realistic mathematics learning content.
\end{abstract}

Keywords: Online Learning, Teaching Materials, Calculus

\begin{abstract}
Abstrak
Program Pemerintah Republik Indonesia melalui kementerian pendidikan dan kebudayaan (Kemendikbud) tentang pembelajaran daring yang telah digagas tahun 2014 terpaksa dipercepat pelaksanaannya secara masal pada tahun 2020 dikarenakan efek dari pandemi covid-19 yang melanda seluruh dunia, termasuk Indonesia. Perubahan pembelajaran tradisional menjadi full daring tentu menjadi tantangan yang cukup besar bagi institusi penyelenggaran pendidikan. Pembelajaran daring tentu membutuhkan pendukung yang relevan, salah satunya bahan ajar. Artikel ini membahas tentang pengembangan bahan ajar kalkulus berbasis daring berbantuan GeoGebra. Tujuan pengembangan bahan ajar tersebut sebagai alternatif agar pembelajaran kalkulus berbasis daring dapat berjalan efektif dan optimal. Metode yang digunakan untuk mengembangkan bahan ajar tersebut adalah dengan jenis penelitian research and development $(R \& D)$ melalui pengujian praktikalitas dan efektfitas bahan ajar dengan instrumen kuisioner dan soal kalkulus dasar pada 20 responden yang merupakan mahasiswa Program Studi Pendidikan Matematika Universitas Teknokrat Indonsesia yang telah mengambil mata kuliah Kalkulus Dasar. Hasil pengujian praktikalitas dan efektifitas bahan ajar ini menunjukan bahwa praktikalitas dan efektifitas bahan ajar ini termasuk kategori baik dengan nilai uji sebesar 3,36 untuk praktikalitas dan 72,75 untuk efektifitas. Artinya bahan ajar kalkulus berbasis daring berbantuan GeoGebra ini dapat diimplementasikan pada pengguna sebagai alternatif pembelajaran kalkulus berbasis daring. Berdasarkan evaluasi hasil kuisioner praktikalitas dan efektfitas bahan ajar ini perlu dipotimalkan lagi pada bagian konten untuk dapat mengembangkan kreativitas pengguna serta pada konten pembelajaran matematika realistik.
\end{abstract}

Kata kunci: Bahan Ajar, Pembelajaran Daring, Kalkulus

\section{PENDAHULUAN}

Berdasarkan laman resmi kemendikbud pada bagian sistem pembelajaran daring (SPADA) tahun 2020 menyebutkan bahwa program Pembelajaran Daring Indonesia Terbuka dan Terpadu (PDITT) yang diluncurkan pada tahun 2014 oleh Wakil Presiden saat itu, Boediono, telah dikembangkan dan berganti nama menjadi Sistem Pembelajaran Daring (SPADA) pada tanggal 18 September 2018. 
Praktikalitas dan Efektifitas Bahan Ajar Kalkulus Berbasis Daring Berbantuan Geogebra, Sugama Maskar, Putri Sukma

Lebih jauh, disebutkan juga bahwa tujuan dari SPADA adalah untuk meningkatkan mutu pembelajaran daring serta sebagai sarana pemerataan pendidikan yang berkualitas di seluruh Indonesia (Admin, 2018).

SPADA merupakan wujud nyata dari keseriusan Pemerintah Republik Indonesia di bawah Kementerian Pendidikan dan Kebudayaan (Kemendikbud) untuk menjawab tantangan Revolusi Industri 4.0 dalam ranah Pendidikan Tinggi. Untuk mendukung kebijakan tersebut diperlukan perangkat ajar yang relevan agar dapat diterapkan secara optimal pada proses pembelajaran daring. Salah satu perangkat ajar tersebut adalah bahan ajar berbasis daring. Menurut Hamdani dalam Maulydia et al. (2017), bahan ajar merupakan kumpulan sumber belajar yang dapat mendukung pengajar dan peserta didik dalam proses pembelajaran. Bahan ajar tersebut dapat berupa materi cetak atau audio visual seperti modul, lembar kerja siswa, brosur, video, gambar, CD interaktif, atau bahan ajar berbasis internet. Era robotik dan IoT (internet of thinks) pada revolusi industri 4.0 tentu seharusnya membawa pengaruh juga pada proses pembelajaran apabila dimanfaatkan dengan baik (Maskar \& Anderha, 2019). Berdasarkan data, pada saat ini pengguna internet di Indonesia mencapai setidaknya 98\% dari keseluruhan penduduk dengan mayoritas pengguna adalah remaja yang masih mengenyam pendidikan di sekolah (P. S. Dewi \& Sintaro, 2019).

Bahan ajar yang berbasis teknologi mencerminkan kemajuan suatu pendidikan serta membawa banyak manfaat bagi pengajar maupun peserta didik. Selain itu, penggunaan bahan ajar menimbulkan efek langsung pada realisasi tujuan pendidikan dalam proses pembelajaran diantaranya peserta didik menjadi lebih tertarik pada materi, menjadi lebih aktif, melakukan lebih banyak latihan sesuai dengan kualitas individu mereka, menjadi lebih sukses, mengalami pembelajaran nyata, dan memberikan kesempatan untuk berkolaborasi, berpikir kritis, dan meningkatkan kemampuan pemecahan masalah (Koparan, 2017). Sumber belajar berbasis internet juga dapat membuat peserta didik menjadi tertarik seperti dalam hal pembuatan kuis. Dengan bantuan internet seorang pengajar dapat mengajukan pertanyaan terbuka yang solusinya dapat peserta didik cari dengan bantuan internet, sehingga penggunaan internet dapat meningkatkan kemampuan tambahan seperti analisa, teknologi, presentasi dan komunikasi (Bušljeta, 2013).

Beberapa penelitian terkait menunjukan bahwa penggunaan bahan ajar optimal dalam meningkatkan kemampuan pemecahan masalah, berpikir matematis, aktivitas pembelajaran, kemampuan penalaran, dan komunikasi matematis (Habsah, 2017; Imswatama \& Lukman, 2018). Namun, tantangan yang harus dihadapi untuk dapat menyusun bahan ajar berbasis daring, salah satunya pada materi matematika. Berdasarkan hasil observasi, para pengajar materi rumpun matematika merasa bahwa pembelajaran matematika sulit diajarkan secara daring. Para pengajar merasa bahwa peserta didik membutuhkan simulasi langsung untuk memahami materi matematika.

Saat ini telah banyak tersedia teknologi yang mampu untuk mensimulasikan pembelajaran matematika dengan sangat baik. GeoGebra merupakan salah satu teknologi yang dapat digunakan untuk mendukung pembelajaran matematika secara daring. Berdasarkan Majerek (2014), GeoGebra 
merupkaan salah satu perangkat lunak matematika dinamis yang direkomendasikan untuk proses pembelajaran. Lebih lanjut, Majerek menyimpulkan bahwa peserta didik pada tingkat pengetahuan matematika level dimanapun dapat didorong untuk belajar matematika dengan menggunakan perangkat lunak ini. GeoGebra sangat cocok dengan tren pembelajaran visualisasi. Sebelumnya, telah banyak penelitian penggunaan GeoGebra pada proses pembelajaran, hasil penelitian tersebut menunjukan bahwa penggunaan GeoGebra membuat peserta didik fokus pada materi, terutama Integral dan mayortias peserta didik mengaku dapat membuat sketsa grafik dengan baik dan benar melalui GeoGebra (N. R. Dewi \& Arini, 2018; Machromah et al., 2019). Namun, penelitian yang telah dilakukan sebatas pada pemanfaatan GeoGebra pada proses pembelajaran yang mayoritas tatap muka. Sangat jarang ditemui bahan ajar disisipkan GeoGebra sebagai media interaktif peserta didik untuk membantu belajar secara mandiri. Paper ini membahas tentang penggunaan GeoGebra pada bahan ajar berbasis daring dengan cara menyematkan media pada bahan ajar yang dikembangkan, salah satunya GeoGebra, sehingga media tersebut dapat dimanfaatkan secara real time pada bahan ajar tersebut.

\section{METODE}

Pengembangan bahan ajar bebasis daring ini dikembangkan dengan menggunakan metode Research and Develpoment $(R \& D)$. Penelitian berbasis pengembangan merupakan metode yang digunakan untuk menghasilkan produk tertentu agar layak diimplementasikan dengan cara dilakukan pengujian (Sugiyono dalam Maskar \& Wulantina, 2019). $R \& D$ merupakan metode penelitian yang digunakan untuk mengembangkan suatu produk. Metode $R \& D$ secara umum menggunakan uji validitas, kepraktisan, dan efektifitas terhadap produk yang diuji melalui pakar dan praktisi terkait. Pengembangan bahan ajar kalkulus bebasis daring ini menggunakan pengembangan model Plomp berikut (Ahmar \& Rahman, 2017; Hikmah \& Maskar, 2020).

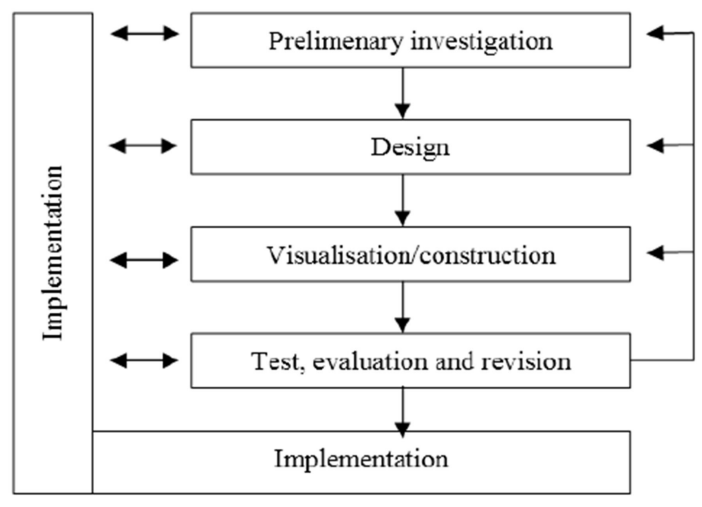

Gambar 1. Desain Penelitian R\&D Plomp

\section{Uji Praktikalitas}


Praktikalitas dan Efektifitas Bahan Ajar Kalkulus Berbasis Daring Berbantuan Geogebra, Sugama Maskar, Putri Sukma Dewi

Praktikalitas merupakan ukuran untuk mengetahui keterpakaian produk yang sedang dibuat oleh pengguna. Ukuran prkatikalitas suatu produk dapat diukur dari kemudahaan dan penyajian suatu produk oleh pengguna (Agustyaningrum \& Gusmania, 2017). Aspek praktikalitas yang di ukur pada paper ini meliputi kemudahan pengguna atau peserta didik dalam menggunakan bahan ajar Kalkulus berbasis daring ini dengan menggunakan lima indikator utama diantaranya; efektifitas, kreativitas, efisiensi, interaktif, dan kemenarikan bahan ajar. Bahan ajar ini diujicobakan pada 20 responden yang merupakan mahasiswa program studi S1 Pendidikan Matematika yang telah mengambil mata kuliah kalkulus dasar. Instumen yang digunakan untuk pengujian merupakan kusioner skala sikap yang terdiri dari 56 pernyataan tertutup dengan 5 indikator yang telah disebutkan sebelumnya. Selain itu, terdapat dua pernyataan terbuka mengenai masukan terhadap kelebihan, kekurangan dan saran terhadap bahan ajar yang dikembangkan.

\section{Uji Efektifitas}

Uji efektifitas bertujuan untuk mengetahui seberapa besar pengaruh bahan ajar kalkulus berbasis daring ini terhadap pemahaman peserta didik pada materi kalkulus dasar. Serupa dengan uji praktiklitas, uji efektifitas juga diujikan pada 20 responden yang sama namun dengan instrumen yang berbeda. Instrumen yang digunakan untuk menguji efektifitas bahan ajar kalkulus daring ini berupa soal-soal mengenai kalkulus dasar yang terdiri dari materi bilangan riil, fungsi dan grafiknya. Soal tersebut bersifat uraian, sehingga penilaian hasil ujian akan dilakuakan dengan menggunakan rubrik penialian untuk menghindari subjektifitas penilaian.

\section{Pengolahan dan Analisis Data}

Data hasil uji praktikalitas dan efektifitas akan diolah dan dianalisa menggunakan kriteria pengujian berdasarkan Widoyoko dalam Rusnilawati \& Gustiana (2017) sebagai berikut:

\section{Tabel 1.}

Kriteria Pengujian Kelayakan Bahan Ajar

\begin{tabular}{|c|c|c|}
\hline Nilai & Interval Skor & Kategori \\
\hline $\mathrm{A}$ & $X>\bar{X}_{i}+1.8 s b_{i}$ & Sangat Baik \\
\hline $\mathrm{B}$ & $\bar{X}_{i}+0.6 s b_{i}<X \leq \bar{X}_{i}+1.8 s b_{i}$ & Baik \\
\hline $\mathrm{C}$ & $\bar{X}_{i}-0.6 s b_{i}<X \leq \bar{X}_{i}+0.6 s b_{i}$ & Cukup \\
\hline $\mathrm{D}$ & $\bar{X}_{i}-1.8 s b_{i}<X \leq \bar{X}_{i}-0.6 s b_{i}$ & Kurang \\
\hline $\mathrm{E}$ & $X \leq \bar{X}_{i}-1.8 s b_{i}$ & Sangat Kurang \\
\hline
\end{tabular}

Keterangan:

$\bar{X}_{i}=$ rerata skor ideal $=\frac{1}{2}($ skor maksimum + skor minimum $)$

$s b_{i}=$ simpangan baku ideal $=\frac{1}{6}($ skkor maksimum - skor minimum $)$

$X=$ skor aktual 
Pengujian dikatakan praktis dan efektif apabila hasil pengujian minimal termasuk kategori Baik.

Sebelum hasil uji praktikalitas diolah dan dianalisa, dilakukan analisa validitas terlebih dahulu pada setiap item pernyataan kuisioner uji praktikalitas bahan ajar kalkulus berbasis daring. Uji validitas tersebut dilakukan menggunakan uji independent sample t-test dengan membandingkan $\mathrm{t}$ hitung dan $t$ tabel.

Langkah pertama pengujian validitas dimulai dari menghitung korelasi hubungan antara skor yang diperoleh setiap subjek dari setiap item pernyataan dengan skor total yang diperoleh dari seluruh item $\left(R_{x y}\right)$ dengan persamaan berikut:

$$
R_{x y}=\frac{N \sum X Y-\left(\sum X\right)\left(\sum Y\right)}{\sqrt{\left(N \sum X^{2}-\left(\sum X\right)^{2}\right)\left(N \sum Y^{2}-\left(\sum Y\right)^{2}\right)}}
$$

Keterangan:

$X \quad=$ Skor yang diperoleh subyek dari seluruh item

$Y \quad=$ Skor total yang diperoleh dari seluruh item

$\sum X=$ Jumlah skor dalam distribusi $\mathrm{X}$

$\sum Y=$ Jumlah skor dalam distribusi $\mathrm{Y}$

$\sum X^{2}=$ Jumlah kuadrat dalam skor distribusi $\mathrm{X}$

$\sum Y^{2}=$ Jumlah kuadrat dalam skor distribusi $Y$

$N \quad=$ Banyaknya responden

Selanjutnya, ditentukan nilai thitung dengan menggunakan formula sebagai berikut:

$$
\text { thitung }=\frac{(\sqrt{N-2}) \times R_{x y}}{\sqrt{1-\left(R_{x y}\right)^{2}}}
$$

Kemudian, nilai $t$-tabel diperoleh menggunakan t-tabel dengan kriteria $\alpha=0.05$ dan $d f=n-2$. Pengambilan keputusan valid atau tidaknya suatu item pernyataan diperoleh apabila nilai $t$-hitung $>t$ tabel, apabila sebaliknya dapat disimpulkan bahwa pernyataan tersebut tidak valid.

\section{HASIL}

\section{Gambaran Bahan Ajar Kalkulus Berbasis Daring berbantuan GeoGebra}

Bahan ajar kalkulus daring berbantuan GeoGebra secara umum disusun menjadi tiga bagian utama, yaitu bagian awal, bagian isi, dan evaluasi. Bagian awal bahan ajar terdiri dari daftar materi pada bahan ajar serta informasi mengenai deskripsi materi kalkulus, capaian pembelajaran lulusan, capaian pembelajaran mata kuliah, dan referensi yang digunakan. Gambar 2 merupakan pindaian layar bahan bagian awal bahan ajar tersebut:

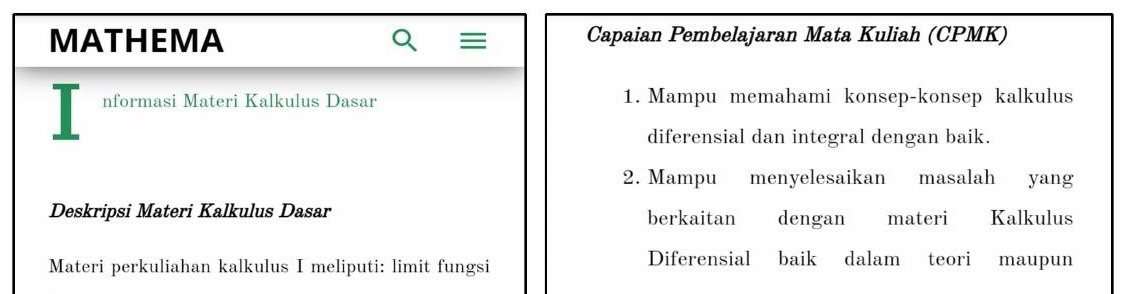


Gambar 2. Bagian Awal Bahan Ajar Kalkulus Daring berbantuan GeoGebra

Selanjtunya, bagian isi bahan ajar ini terdiri dari materi kalkulus dasar. Materi tersebut dipaparkan melalui bantuan media utama, yaitu perangkat lunak GeoGebra, serta beberapa media pendukung diantaranya; penggunaan YouTube, latex online, serta media evaluasi online. Penggunaan media tersebut bertujuan agar materi kalkulus yang disajikan pada bahan ajar ini dapat diilusstrasikan dan dipahami dengan baik oleh pengguna. Gambar 3 merupakan pindaian layar dari bagian isi bahan ajar kalkulus berbasis daring berbantuan GeoGebra ini.

Bagain terakhir pada bahan ajar ini adalah evaluasi. Pengguna selain dapat belajar kalkulus melalui bahan ajar ini, juga dapat melakukan evaluasi terhadap dirinya sendiri untuk mengetahui sejauh mana pemahaman pengguna pada saat mempelejari materi kalkulus dasar. Terdapat dua bagian evaluasi pada bahan ajar ini, pertama pada bagian aktivitas yang disajikan pada pertengahan materi serta pada bagian latihan pada bagian akhir materi.

\begin{tabular}{|c|c|}
\hline MATHEMA & MATHEMA \\
\hline $\begin{array}{l}\text { Aktivitas. } \\
\text { 1). Buatlah tabel beberapa daerah asal dan hasil } \\
\text { dari fungsi yang diberikan pada Contoh } 2 \text {. Sebagai } \\
\text { gambaran, contoh pembuatan grafik fungsi } \\
\text { sederhana secara manual dapat dilihat pada video } \\
\text { berikut: } \\
\text { Cara menggambar sk... }\end{array}$ & $\begin{array}{l}\text { istem Bilangan Riil } \\
\text { Ilmu kalkulus didasarkan pada sistem bilangan riil } \\
\text { dan sifat-sifatnya. Untuk memahami apa itu } \\
\text { bilangan riil, terlebih dahulu dibahas bilangan yang } \\
\text { lebih sederhana yang dapat ditemui pada kehidupan } \\
\text { sehari-hari. Bilangan sederhana tersebut } \\
\text { diantaranya sebagai berikut: } \\
\text { 1. Himpunan bilangan asli, } \\
\qquad \mathbb{N}=\{1,2,3,4,5,6, \ldots\} \\
\text { 2. Himpunan bilangan bulat, } \\
\quad \mathbb{Z}=\{\ldots,-3,-2,-1,0,1,2,3, \ldots\} \\
\text { 3. Himpunan bilangan rasional, } \\
\quad \mathbb{Q}=\left\{\frac{a}{b} \mid a, b \in \mathbb{Z}, b \neq 0\right\}\end{array}$ \\
\hline $\begin{array}{l}\text { 2). Gambakan grafik fungsi berikut: (a) } \\
\qquad x^{2}-1\end{array}$ & $\begin{array}{l}\text { Selain yang disebutkan di atas, terdapat juga } \\
\text { bilangan irasional diantaranya; }\end{array}$ \\
\hline
\end{tabular}

Gambar 3. Bagian Isi Bahan Ajar Kalkulus Daring berbantuan GeoGebra

\begin{tabular}{|c|c|}
\hline Latihan Materi Fungsi dan Grafiknya & MATHEMA $Q \equiv$ \\
\hline $\begin{array}{l}\text { 1). Untuk } \\
\qquad f(x)=2 x^{2}-1 \\
\text {, hitunglah masing-masing nilai berikut: } \\
\text { (a) }\end{array}$ & $\begin{array}{l}\text { Aktivitas } \\
\text { 1). Tunjukan masing-masing selang berikut pada } \\
\text { garis riil. } \\
\text { a. }(-3,1)\end{array}$ \\
\hline
\end{tabular}


Gambar 4. Bagian Evaluasi Bahan Ajar Kalkulus Daring berbantuan GeoGebra

\section{Hasil Uji Praktikalitas}

Bahan ajar kalkulus daring telah diujikan pada 20 responden yang merupakan mahasiswa program studi S1 Penddidikan Matematika yang telah mengambil mata kuliah Kalkulus Dasar. Berdasarkan hasil angket uji praktikalitas pada 20 responden, kriteria pengambilan keputusan akan mengacu pada rentang nilai yang terdapat pada tabel 7 berikut:

\section{Tabel 7.}

Kriteria Pengujian Praktikalitas Bahan Ajar

\begin{tabular}{|c|c|c|}
\hline Nilai & Interval Skor & Kategori \\
\hline A & $X>3,6$ & Sangat Baik \\
\hline B & $3,20<X \leq 3,6$ & Baik \\
\hline C & $2,80<X \leq 3,20$ & Cukup \\
\hline D & $2,4<X \leq 2,80$ & Kurang \\
\hline E & $X \leq 2,4$ & Sangat Kurang \\
\hline
\end{tabular}

Tabel 7 menunjukan bahwa, praktikalitas bahan ajar kalkulus berbasis daring dikatakan praktis apabila memperoleh nilai angket di atas 3,20. Adapun hasil angket praktikalitas untuk 20 responden tersebut terdapat pada tabel 8 .

\section{Tabel 8.}


Hasil Pengujian Praktikalitas Bahan Ajar

\begin{tabular}{|c|c|c|}
\hline No & Indikator & Rerata skor \\
\hline 1 & Efektif & 3,32 \\
\hline 2 & Kreatif & 3,29 \\
\hline 3 & Efisien & 3,41 \\
\hline 4 & Interaktif & 3,36 \\
\hline 5 & Menarik & 3,43 \\
\hline \multicolumn{2}{|c|}{ Rerata } & 3,36 \\
\hline
\end{tabular}

Berdasarkan tabel 8 dapat dilihat bahwa nilai rerata skor dari lima indikator dan 56 pernyataan tersebut sebesar 3,36. Berdasarkan kriteria pada tabel 8, dapat disimpulkan bahwa bahan ajar kalkulus daring termasuk kategori baik. Lebih jauh, setiap indikator pada pada angket praktikalitas mendapatkan skor lebih dari 3,20. Artinya setiap indikator tersebut juga mempunyai nilai mutu yang baik berdasarkan penilaian praktisi.

\section{Hasil Uji Efektifitas}

Selanjutnya, pengujian efektifitas dilakukan melalui instrumen soal yang bertujuan untuk mengetahui pengaruh penggunaan bahan ajar kalkulus berbasis daring pada penggunanya. Berdasarkan skor hasil uji efektifitas, berikut kriteria pengambilan keputusan efektifitas bahan ajar kalkulus berbasis daring terdapat pada tabel 9 .

\section{Tabel 9.}

Kriteria Pengujian Efektifitas Bahan Ajar

\begin{tabular}{|c|c|c|}
\hline Nilai & Interval Skor & Kategori \\
\hline A & $X>76$ & Sangat Baik \\
\hline B & $67<X \leq 76$ & Baik \\
\hline C & $58<X \leq 67$ & Cukup \\
\hline D & $49<X \leq 58$ & Kurang \\
\hline E & $X \leq 49$ & Sangat Kurang \\
\hline
\end{tabular}

Berikut hasil uji efektifitas dari 20 responden pada tabel 10.

\section{Tabel 10.}

Hasil Pengujian Efektifitas Bahan Ajar

\begin{tabular}{|c|c|}
\hline Responden & Nilai Rerata \\
\hline 1 & 75 \\
\hline 2 & 80 \\
\hline 3 & 67,5 \\
\hline 4 & 77,5 \\
\hline 5 & 70 \\
\hline 6 & 72,5 \\
\hline 7 & 75 \\
\hline 8 & 72,5 \\
\hline 9 & 72,5 \\
\hline 10 & 80 \\
\hline 11 & 80 \\
\hline
\end{tabular}




\begin{tabular}{|c|c|}
\hline Responden & Nilai Rerata \\
\hline 1 & 75 \\
\hline 12 & 85 \\
\hline 13 & 60 \\
\hline 14 & 85 \\
\hline 15 & 72,5 \\
\hline 16 & 70 \\
\hline 17 & 75 \\
\hline 18 & 85 \\
\hline 19 & 40 \\
\hline 20 & 60 \\
\hline Rerata & $\mathbf{7 2 , 7 5}$ \\
\hline
\end{tabular}

Tabel 10 menunjukan bahwa total rerata hasil uji soal kalkulus dasar pada 20 responden memperoleh nilai 72,75. Artinya berdasarkan kriteria pengujian pada tabel 9, nilai mutu rerata total tersebut termasuk dalam kategori baik, dengan kata lain bahan ajar kalkulus berbasis daring tersebut terbukti efektif berdasarkan penilaian 20 responden tersebut.

Hasil pengujian praktikalitas dan efektifitas menunjukan bahwa berdasarkan 20 responden yang terpilih, bahan ajar kalkulus daring yang dikembangkan menunukan hasil praktis dan efektif. Artinya, bahan ajar tersebut layak digunakan dan diimplementasikan pada pengguna untuk mempelajari materi kalklus dasar. Berdasarkan tabel 8, skor tertinggi penilaian praktisi pada uji praktikalitas terletak pada indikator kemenarikan bahan ajar dan skor paling rendah terdapat pada indikator kreativitas bahan ajar. Kreativitas disini berarti bahan ajar tersebut mampu menumbuhkan sisi kreatif penggunasetelah menggunakannya pada materi kalkulus. Berdasarkan hal tersebut, perlu adanya perbaikan konten dan aspek lainnya untuk meningkatkan krativitas pengguna setelah menggunakan bahan ajar tersebut. Ada beberapa hal yang perlu diperkuat, diantaranya memasukan model pembelajaran AIR atau Auditory, Intellectually, dan Repetition. AIR merupakan suatu model yang menekankan bahwa suatu bahan ajar harus mempu menekankan pada aspek mendengarkan, berbicara, argumentasi, mengemukakan, presentasi dan menanggapi. Selain itu, bahan ajar juga perlu menggunakan kemampuan berpikir seperti bernalar, mengidentifikasi, menemukan, mencipta, memecahkan masalah dan lainnya. Terakhir, bahan ajar harus menumbuhkan sikap ingin tahu siswa sehingga siswa dapat melakukan pendalaman materi dengan berbagai cara (Manurung, 2016). Selain itu, peningkatan kreativitas juga dapat dilakukan dengan cara mengintegrasikan materi kalkulus dengan rumpun ilmu lainnya seperti sains, teknologi, atau mekanika. Sebagai rujukan, penentuan konten terintegrasi tersbut dapat merujuk pada prgram terintegrasi STEM (Scinece, Technology, Engineering, and Mathematics) (Ismayani, 2016).

Selanjutnya pada aspek efektifitas. Hasil uji tes berbentuk soal uraian kalkulus dasar mendapat skor rerata sebesar 72,55 dengan skor rerata per responden tertinggi sebesar 85 dan terendah sebesar 40. Berdasarkan informasi tersebut, masih terdapat pengguna atau peserta didik yang mendapatkan skor rendah setelah belajar menggunakan bahan ajar kalkulus berbasis daring yang dikembangkan. 
Praktikalitas dan Efektifitas Bahan Ajar Kalkulus Berbasis Daring Berbantuan Geogebra, Sugama Maskar, Putri Sukma Dewi

Perlu adanya evaluasi mendasar mengenai strategi atau metode pembelajaran yang disematkan pada bahan ajar tersebut agar lebih efektif dalam meningkatkan pemahaman matematis pengguna, khususnya pada materi kalkulus dasar. Salah satu cara yang dapat dilakukan untuk meningkatkan pemahaman pengguna yaitu dengan memperbanyak kaitan materi dengan kehidupan sehari-hari atau lebih dikenal dengan matematika realistik. Bahan ajar berbasis matematika realistik dinilai efektif untuk dapat meningkatkan kemampuan penalaran dan komunikasi matematis peserta didik. Materi terkait matematika realistik perlu dikembangan dengan memperhatikan berberapa aspek diantaranya; 1). Materi yang dikembangkan perlu diimbangi oleh ilustrasi yang relevan dan menarik; 2). Materi menggunakan bahasa yang baik dan sesuai dengan keseharian dan budaya mayoritas pengguna; 3 ). Materi ajar perlu disusun dengan menambahkan tugas kegiatan, diskusi, soal-soal latihan, bahkan soal proyek; 4). Materi ajar disajikan dengan mempertimbangkan perkembangan karakter, mental dan akhlak yang baik dari pengguna (Maskar, 2018). Lebih lanjut, penelitian tersebut juga menunjukan bahwa bahan ajar matematika yang dikembangkan lebih efektif dibandingkan Buku Sekolah Elektronik (BSE) dalam hal meningkatkan kemampuan penalaran dan komunikasi matematis peserta didik (Habsah, 2017). Selanjutnya, dapat dilakukan dengan memperbanyak penggunaan media GeoGebra pada bahan ajar tersebut. Salat satu perangkat lunak matematika dinamis yang dapat dijadikan media pembelajaran terutama pada bidang geometri adalah GeoGebra. Dengan program GeoGebra objek-objek geometri yang bersifat abstrak dapat divisualisasi dan dimanipulasi secara cepat, akurat, dan efisien (Mahmudi dalam Japa et al., 2017). Sesungguhnya, bahan ajar yang dikembangkan telah menggunakan media GeoGebra sebagai alat bantu utuk mensimulasikan grafik fungsi dan bagian abstrak lainnya. Namun, perlu penambahan dan penempatan penggunaan penyematan GeoGebra secara tepat agar hasilnaya lebih optimal.

Lebih jauh, berdasarkan hasil uji, bahan ajar kalkulus berbasis daring berbantuan GeoGebra ini telah dinyatakan layak dan bernilai baik sehingga telah dapat diimplementasikan sebagai salah satu alternatif bahan ajar berbasis daring. Maraknya penggunaan pembelajaran berbasis daring sebagai akibat dari adanya pandemi covid-19 ini tentu memberikan tantangan bagi pelaku pendidikan maupun peneliti untuk dapat mengembangkan bahan ajar berbasis daring yang dapat digunakan secara optimal sehingga proses pembelajaran daring dapat berjalan efektif. Bahan ajar kalkulus daring yang dikembangkan ini selain menyematkan GeoGebra yang dapat digunakan secara real time, namun juga terdapat beberapa media lain yang disematkan juga seperti video dari laman YouTube, penggunaan evaluasi online dan penulisan simbol matematika menggunakan latex online. Diharapkan bahan ajar kalkulus daring berbantuan GeoGebra ini dapat optimal membantu proses pembelajaran daring dan menjadi salah satu solusi pembelajaran matematika secara daring di tengah-tengah pandemi covid-19 dan seterusnya.

\section{KESIMPULAN}


Bahan ajar kalkulus berbasis daring berbantuan GeoGebra ini dikembangkan dengan kelebihan pada media pembelajaran yang disematkan dari berbagai platform dan perangkat lunak agar dapat digunakan secara real time dan juga dapat membantu pengguna dalam memahami materi yang diberikan mengenai kalkulus dasar. Media tersebut diantaranya GeoGebra, video dari YouTube, penggunaan Latex Online, evaluasi online berupa kuis atau ujian daring secara real time.

Berdasarkan hasil pengujian praktisi untuk menguji praktikalitas dan efektifitas bahan ajar, menunjukan bahwa bahan ajar tersebut termasuk kategori praktis dan efektfif, dengan kata lain bahan ajar yang dikembangkan tersebut dapat diimplementasikan sebagai alternatif bahan ajar daring untuk materi kalkulus dasar. Niai uji praktikalitas dan efektifitas bahan ajar kalkulus daring berbantuan GeoGebra ini terletak pada level baik. Berdasarkan nilai per indikator angket praktikalitas dan efektifitas, beberapa hal yang perlu ditingkatkan pada bahan ajar ini diantaranya mengenai konten untuk mengembangkan krativitas pengguna serta pengembangan materi berbasis matematika realistik.

Bahan ajar ini telah dapat diimplementasikan, sehingga disarankan pada pendidik, pengguna atau pihak-pihak yang berkaitan dengan pembelajaran atau pendidikan yang relevan dengan materi kalkulus dasar dapat menggunakan bahan ajar ini sebagai alternatif untuk belajar. Selain itu, disarankan juga untuk memberikan kritik dan saran terkait pengembangan bahan ajar ini agar dapat memberikan hasil yang optimal pada pengguna.

\section{DAFTAR PUSTAKA}

Admin. (2018). Sistem Pembelajaran Daring (SPADA). Kemendikbud. www.spada.kemendikbud.go.id

Agustyaningrum, N., \& Gusmania, Y. (2017). Praktikalitas Dan Keefektifan Modul Geometri Analitik Ruang Berbasis Konstruktivisme. Jurnal Dimensi, 6(3), 412-420. https://doi.org/10.33373/dms.v6i3.1075

Ahmar, A. S., \& Rahman, A. (2017). Development of teaching material using an Android. Global Journal of Engineering Education, 19(1), 72-76. https://doi.org/10.26858/gjeev19i1y2017p7376

Bušljeta, R. (2013). Effective Use of Teaching and Learning Resources. Czech-Polish Historical and Pedagogical Journal, 5(2), 55-69. https://doi.org/10.2478/cphpj-2013-0014

Dewi, N. R., \& Arini, F. Y. (2018). Developing calculus textbook model that supported with GeoGebra to enhancing students' mathematical problem solving and mathematical representation. Journal of Physics: Conference Series, 983(1). https://doi.org/10.1088/1742$6596 / 983 / 1 / 012154$

Dewi, P. S., \& Sintaro, S. (2019). Mathematics Edutainment Dalam Bentuk Aplikasi Android. Triple $S, 2(1), 1-11$.

Habsah, F. (2017). Developing teaching material based on realistic mathematics andoriented to the mathematical reasoning and mathematical communication. Jurnal Riset Pendidikan Matematika, 4(1), 43. https://doi.org/10.21831/jrpm.v4i1.10199 
Praktikalitas dan Efektifitas Bahan Ajar Kalkulus Berbasis Daring Berbantuan Geogebra, Sugama Maskar, Putri Sukma

Hikmah, S. N., \& Maskar, S. (2020). PEMANFAATAN APLIKASI MICROSOFT POWERPOINT PADA. Jurnal Ilmiah Matematika Realistik, 1(1), 15-19.

Imswatama, A., \& Lukman, H. S. (2018). The Effectiveness of Mathematics Teaching Material Based on Ethnomathematics. International Journal of Trends in Mathematics Education Research, 1(1), 35. https://doi.org/10.33122/ijtmer.v1i1.11

Ismayani, A. (2016). Pengaruh Penerapan STEM Project - Based Learning terhadap Kreativitas Matematis Siswa SMK. Indonesian Digital Journal of Mathematics and Education, 3, 264-272. https://doi.org/2407-8530

Japa, N., Suarjana, I. M., \& Widiana, W. (2017). Media Geogebra Dalam Pembelajaran Matematika. International Journal of Natural Science and Engineering, 1(2), 40-47. https://doi.org/10.23887/IJNSE.V1I2.12467

Koparan, T. (2017). Analysis of Teaching Materials Developed by Prospective Mathematics Teachers and Their Views on Material Development. Malaysian Online Journal of Educational Technology, 5(4), 8-28.

Machromah, I. U., Purnomo, M. E. R., \& Sari, C. K. (2019). Learning calculus with geogebra at college. Journal of Physics: Conference Series, 1180(1). https://doi.org/10.1088/1742$6596 / 1180 / 1 / 012008$

Majerek, D. (2014). APPLICATION OF GEOGEBRA FOR TEACHING MATHEMATICS. Advances in Science and Technology Research Journal, 8(January), 51-54. https://doi.org/10.12913/22998624/567

Manurung, S. H. (2016). Upaya Meningkatkan Kreativitas Dan Hasil Belajar Siswa Dengan Menggunakan Model AIR (Auditory, Intellectually, Repetition) Pada Siswa Kelas VII MTs Negeri Rantauprapat T.P 2014/2015. Jurnal EduTech, 2(1), 97-107.

Maskar, S. (2018). Alternatif Penyusunan Materi Ekspresi Aljabar Untuk Siswa Smp/Mts Dengan Pendekatan Pendidikan. Prisma, VII(1), 53-69.

Maskar, S., \& Anderha, R. R. (2019). Pembelajaran transformasi geometri dengan pendekatan motif kain tapis lampung. Mathema Journal, 1(1), 40-47.

Maskar, S., \& Wulantina, E. (2019). Persepsi Peserta Didik terhadap Metode Blended Learning dengan Google Classroom. 1(2), 110-121.

Maulydia, S. S., Surya, E., \& Syahputra, E. (2017). The Development Of Mathematic Teaching Material Through The Development Of Mathematic Teaching Material Through Realistic Mathematics Education To Increase Mathematical Problem Solving. International Journal Of Advance Research And Innovative Ideas In Education, 3(2), 2965-2971.

Rusnilawati, \& Gustiana, E. (2017). Pengembangan Bahan Ajar Elektronik (Bae) Berbantuan Flipbook Berbasis Keterampilan Pemecahan Masalah Dengan Pendekatan Ctl Pada Pembelajaran Matematika Kelas V Sekolah Dasar. Profesi Pendidikan Dasar, 4(2), 190-201. https://doi.org/10.23917/ppd.v1i2.5450 